\title{
Application of the Tensegrity Principles on Tensile Textile Constructions
}

\author{
Diana Maritza PEÑA*, ${ }^{*}$, Dr. Ignasi LLORENS ${ }^{a}$, Dr. Ramon SASTRE ${ }^{b}$
}

\author{
*Doctorate Student UPC - C/Perea 1-3 11 ${ }^{\circ} 2^{\text {a }}$ CP. 08035 Barcelona-Spain.

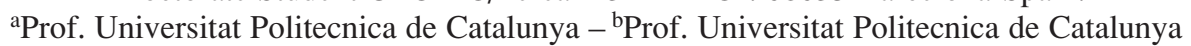

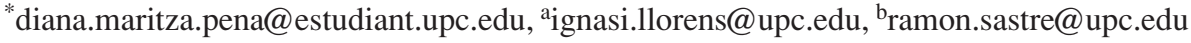

(Received 20/10/09 - Revised version 15/01/10 Acceptation 05/02/10)

\begin{abstract}
The purpose of this document is to study the application of Tensegrity principles on tensile textile constructions, which is one of points of the $\mathrm{PhD}$ Thesis that the author is writing under the tutorship of Prof. Josep Ignasi Llorens and Prof. Ramon Sastre, professors at the Polytechnic University of Catalunia. This work studies the basic concept of Tensegrity unit, its classification according a previous researcher (Anthony Pugh) and the author's contribution, focused on new generations of forms. Through the geometry and computer software, another typology and a constructive simple method is developed, bearing in mind, some aspects as important as system pretension to find its balance.

The objective principal is to contribute in a particular way to the application of the tensegrity in architectural spaces, in this case sports spaces through a new proposal that generates an external ring in tensegrity with a central dome, free of any interior support, by formfinding a diamond membrane pattern with discontinuous struts in a double layer that find their equilibrium through the tension of the membrane.

In the following examples one can observe that traditional tensegrity tendons are replaced by membranes Fig 1 , which is the main contribution of this work that finds geometry and its constructive method of the different prototypes with the help of software like AutoCAD and WinTess (a software development by Ramon Sastre), which verifies the structural equilibrium.
\end{abstract}

Key Words: Tensegrity Unit, Formfinding, Continuous Membrane, Diamond Pattern, Single Layer, Double Layer, Constructive Method, Pretension.

\section{DEFINITION OF TENSEGRITY}

The tensegrity geometry is defined by the equilibrium of tensile and compressive forces. The tensegrity geometry is characterized for having discontinuous compression bars, which remain in equilibrium by tensed cables. The balance is achieved because all the compression and tension forces are perfectly distributed, that is to say work jointly, where the structural form is guaranteed because finally the system is closed and auto-balanced, as Fuller [1] had said "Islands of compression in an ocean of tensions".

"Tensegrity describes a closed structural system composed of a set of three or more elongate compression struts within a network of tension tendons, the combined parts mutually supportive in such a way that the struts do not touch one another, but press outwardly against nodal points in the tension network to form a firm, triangulated, prestressed, tension and compression unit." [2]

"A tensegrity system is established when a set of discontinuous compressive components interacts with a set of continuous tensile components to define a stable volume in space" [3]

\section{PRECEDENTS}

Tensegrity is a developing and relatively new system (more than 50 years old). Three men have been considered the inventors of tensegrity: Richard Buckminster Fuller (USA-1962), David Georges Emmerich (France-1964) and Kenneth D. Snelson (USA-1948). Although all of the three have claimed to be the first inventor, R. Motro mentions that Emmerich 


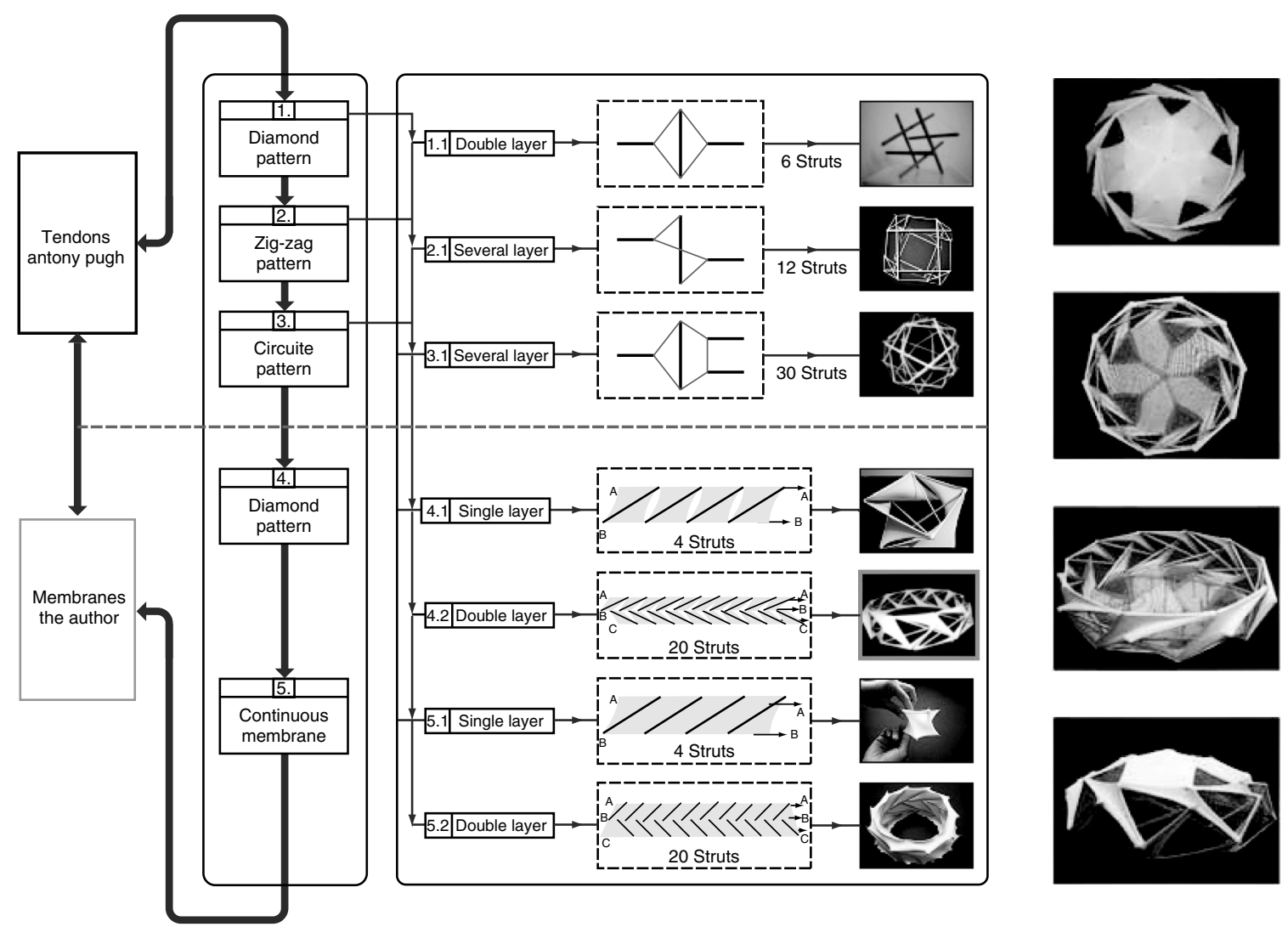

Figure 1. A comparision scheme between Anthony Pugh and a proposal by the author

reported that the first proto-tensegrity system, called "Gleichgewichtkonstruktion", was created by Karl Ioganson (Russia-1920). After in 1976 Anthony Pugh of the University of California (Berkeley) wrote his book "An Introduction to Tensegrity" where he showed and described different models; in addition he did a classification of the diverse existing typology [3]. He described three models, or basic patterns, with which the tensegrity structures can be constructed: a diamond pattern, a zigzag pattern and a circuit pattern. This classification originates from the relative position of the bars amongst themselves and the ends of the tendons [4]. This work rises from Anthony Pugh's classification of the diamond pattern and the position of the bars aligned in a single layer or a double layer, and proposes models using a continuous membrane and a diamond pattern.

\section{FORMFINDING BY GEOMETRY}

The tensegrity geometric construction of this study is based on:

- The conception of a basic module or tensegrity unit from polygons and polyhedrons (prisms and anti-prisms), Platonic and Archimedean solids. [5]

- The substitution of geometric components like edges and vertices by bars, cables and joints by faces in membranes.
- $\quad$ Forming more complex systems from groups and variations of the basic module.

Examples of different scales models in tensegrity with cables and membrane patterns. After we chose some of the models to define a classification and to do the structural analysis:

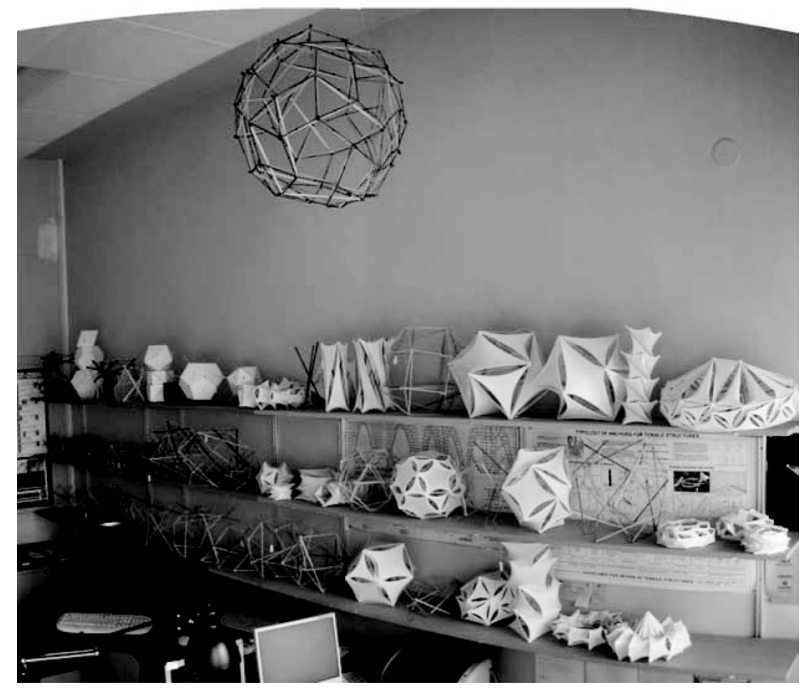

Figure 2. Examples of sixty scales models in tensegrity. Models constructed with an intuitive and experimental method based on the geometry. (Test with different materials) 


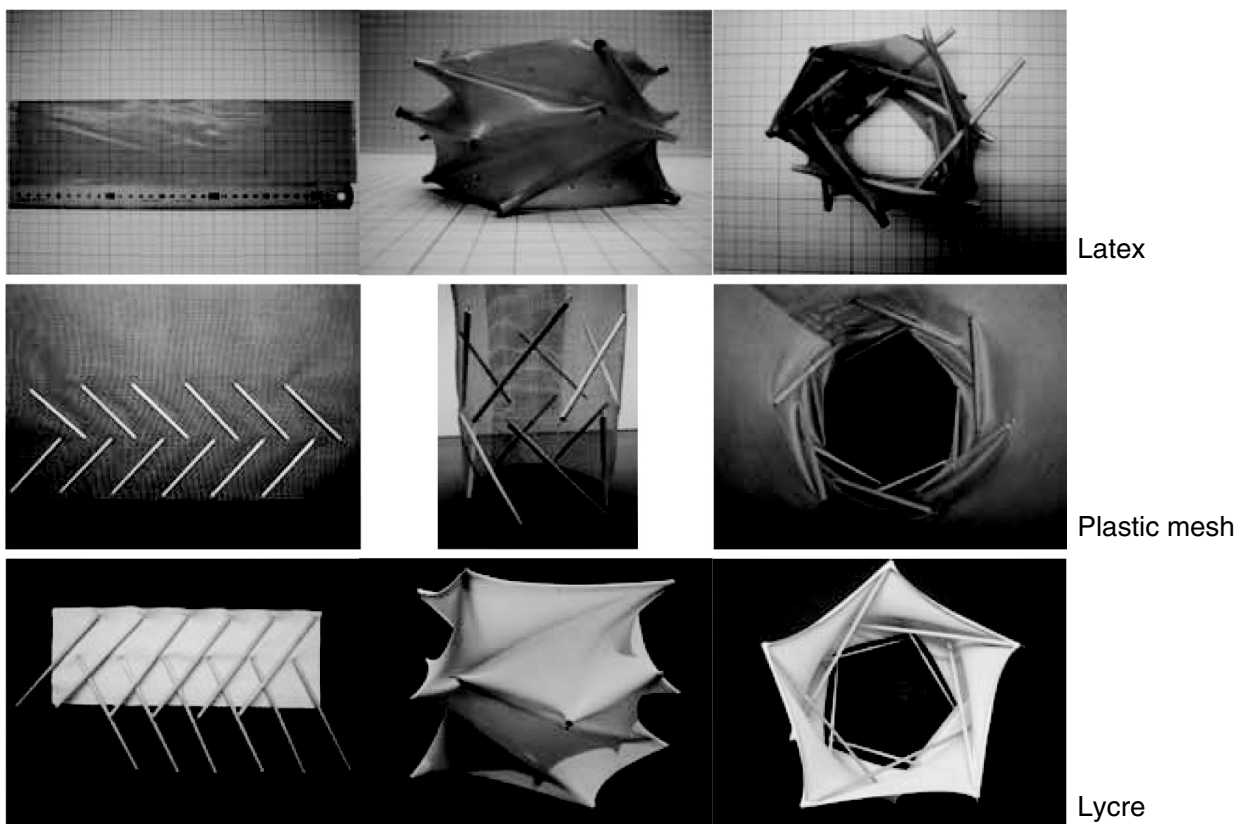

Figure 3. Models examples in different materials. The membrane in lycre is the material chosen to construct the scale models
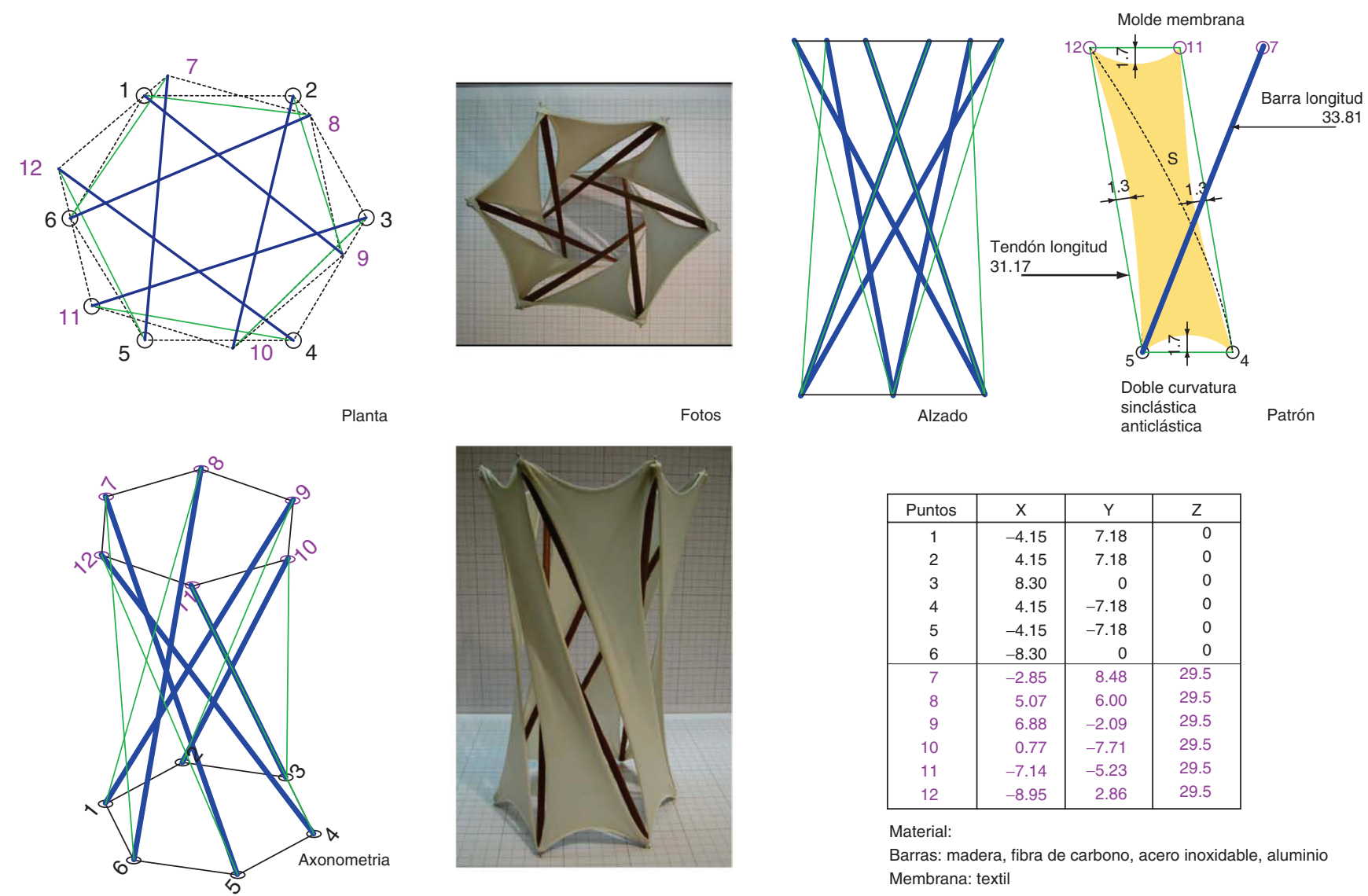

\begin{tabular}{|c|r|r|r|}
\hline Puntos & \multicolumn{1}{|c|}{$\mathrm{X}$} & \multicolumn{1}{|c|}{$\mathrm{Y}$} & \multicolumn{1}{c|}{$\mathrm{Z}$} \\
\hline 1 & -4.15 & 7.18 & 0 \\
2 & 4.15 & 7.18 & 0 \\
3 & 8.30 & 0 & 0 \\
4 & 4.15 & -7.18 & 0 \\
5 & -4.15 & -7.18 & 0 \\
6 & -8.30 & 0 & 0 \\
\hline 7 & -2.85 & 8.48 & 29.5 \\
8 & 5.07 & 6.00 & 29.5 \\
9 & 6.88 & -2.09 & 29.5 \\
10 & 0.77 & -7.71 & 29.5 \\
11 & -7.14 & -5.23 & 29.5 \\
12 & -8.95 & 2.86 & 29.5 \\
\hline
\end{tabular}

Material:

Barras: madera, fibra de carbono, acero inoxidable, aluminio Membrana: textil

Figure 4. A tensegrity unit with 6 struts in a single layer - Geometric description 

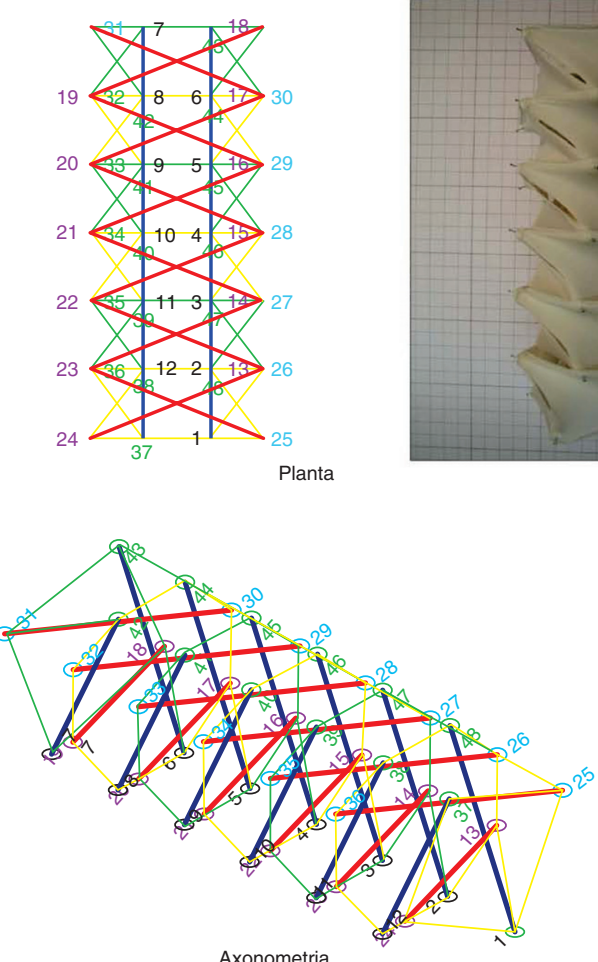

Axonometria
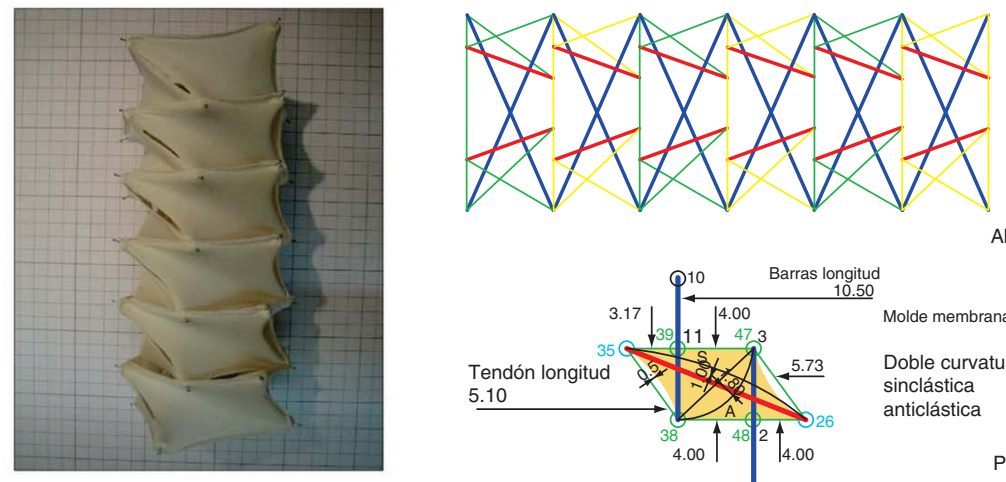

Alzado

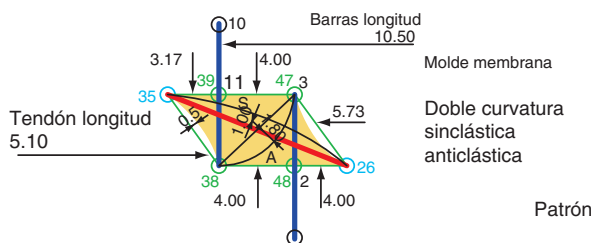

\begin{tabular}{|c|r|r|c|c|c|c|c|}
\hline Puntos & $\mathrm{X}$ & \multicolumn{1}{|c|}{$\mathrm{Y}$} & $\mathrm{Z}$ & Puntos & $\mathrm{X}$ & $\mathrm{Y}$ & $\mathrm{Z}$ \\
\hline 1 & 0 & 0 & 0 & 25 & 2.50 & 0 & 2.50 \\
2 & 0 & 4 & 0 & 26 & 2.50 & 4 & 2.50 \\
3 & 0 & 8 & 0 & 27 & 2.50 & 8 & 2.50 \\
4 & 0 & 12 & 0 & 28 & 2.50 & 12 & 2.50 \\
5 & 0 & 16 & 0 & 29 & 2.50 & 16 & 2.50 \\
6 & 0 & 20 & 0 & 30 & 2.50 & 20 & 2.50 \\
\hline 7 & -4 & 24 & 0 & 31 & -6.00 & 24 & 8.00 \\
8 & -4 & 20 & 0 & 32 & -6.00 & 20 & 8.00 \\
9 & -4 & 16 & 0 & 33 & -6.00 & 16 & 8.00 \\
10 & -4 & 12 & 0 & 34 & -6.00 & 12 & 8.00 \\
11 & -4 & 8 & 0 & 35 & -6.00 & 8 & 8.00 \\
12 & -4 & 4 & 0 & 36 & -6.00 & 4 & 8.00 \\
\hline 13 & 2.5 & 4 & 2.50 & 37 & -4 & 0 & 9.50 \\
14 & 2.5 & 8 & 2.50 & 38 & -4 & 4 & 9.50 \\
15 & 2.5 & 12 & 2.50 & 39 & -4 & 8 & 9.50 \\
16 & 2.5 & 16 & 2.50 & 40 & -4 & 12 & 9.50 \\
17 & 2.5 & 20 & 2.50 & 41 & -4 & 16 & 9.50 \\
18 & 2.5 & 24 & 2.50 & 42 & -4 & 20 & 9.50 \\
\hline 19 & -6.5 & 20 & 4.00 & 43 & 0 & 24 & 9.50 \\
20 & -6.5 & 16 & 4.00 & 44 & 0 & 20 & 9.50 \\
21 & -6.5 & 12 & 4.00 & 45 & 0 & 16 & 9.50 \\
22 & -6.5 & 8 & 4.00 & 46 & 0 & 12 & 9.50 \\
23 & -6.5 & 4 & 4.00 & 47 & 0 & 8 & 9.50 \\
24 & -6.5 & 0 & 4.00 & 48 & 0 & 4 & 9.50 \\
\hline
\end{tabular}

Material:

Barras: madera, fibra de carbono, acero inoxidable, aluminio Cerramento: Iona, textil

Figure 5. Six tensegrity units each one with 4 struts in a single layer - Geometric description. This example can be used like a path way or bridge

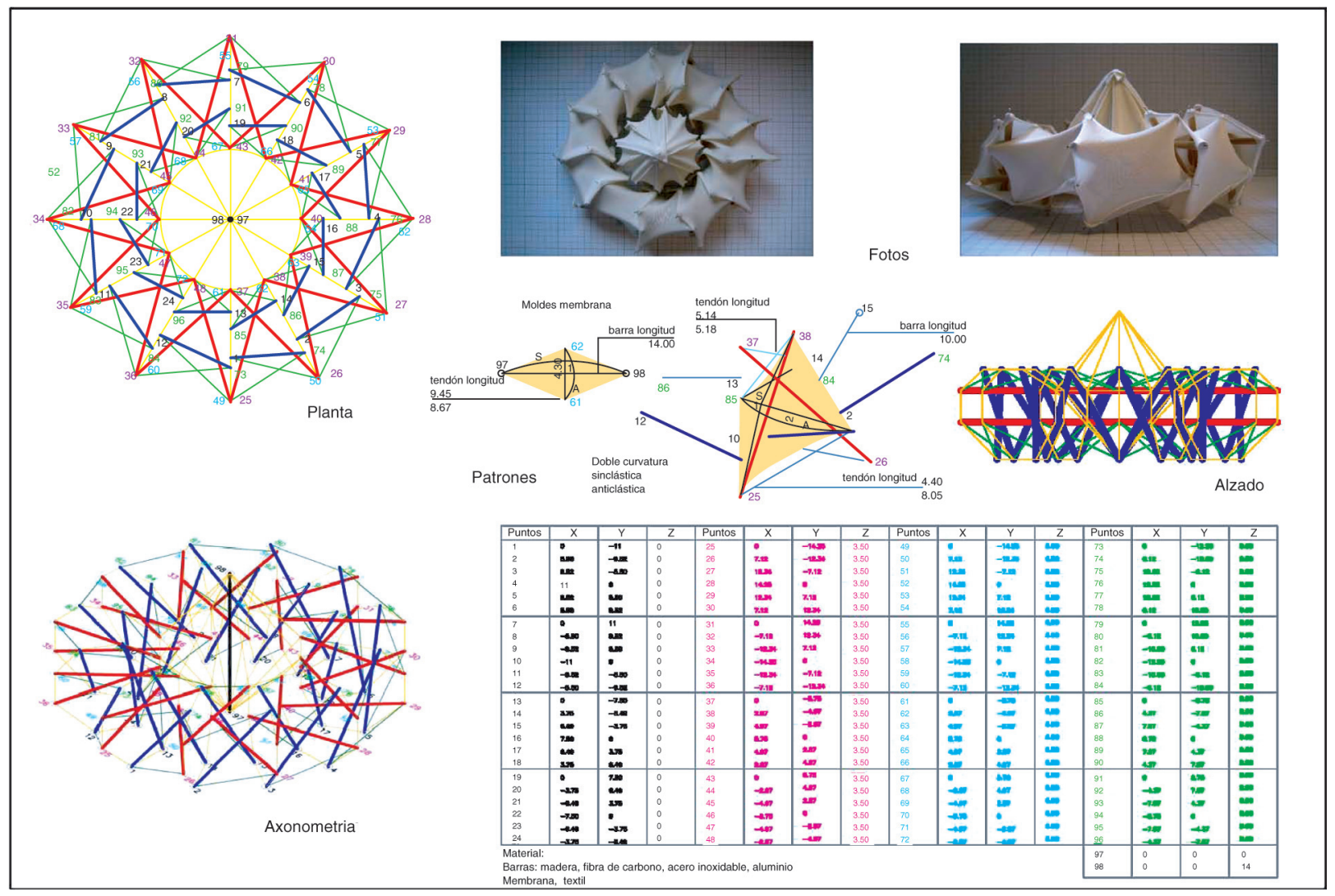

Figure 6. Twelve tensegrity units each one with 4 struts in a single layer (Torus with central mast) - Geometric description 


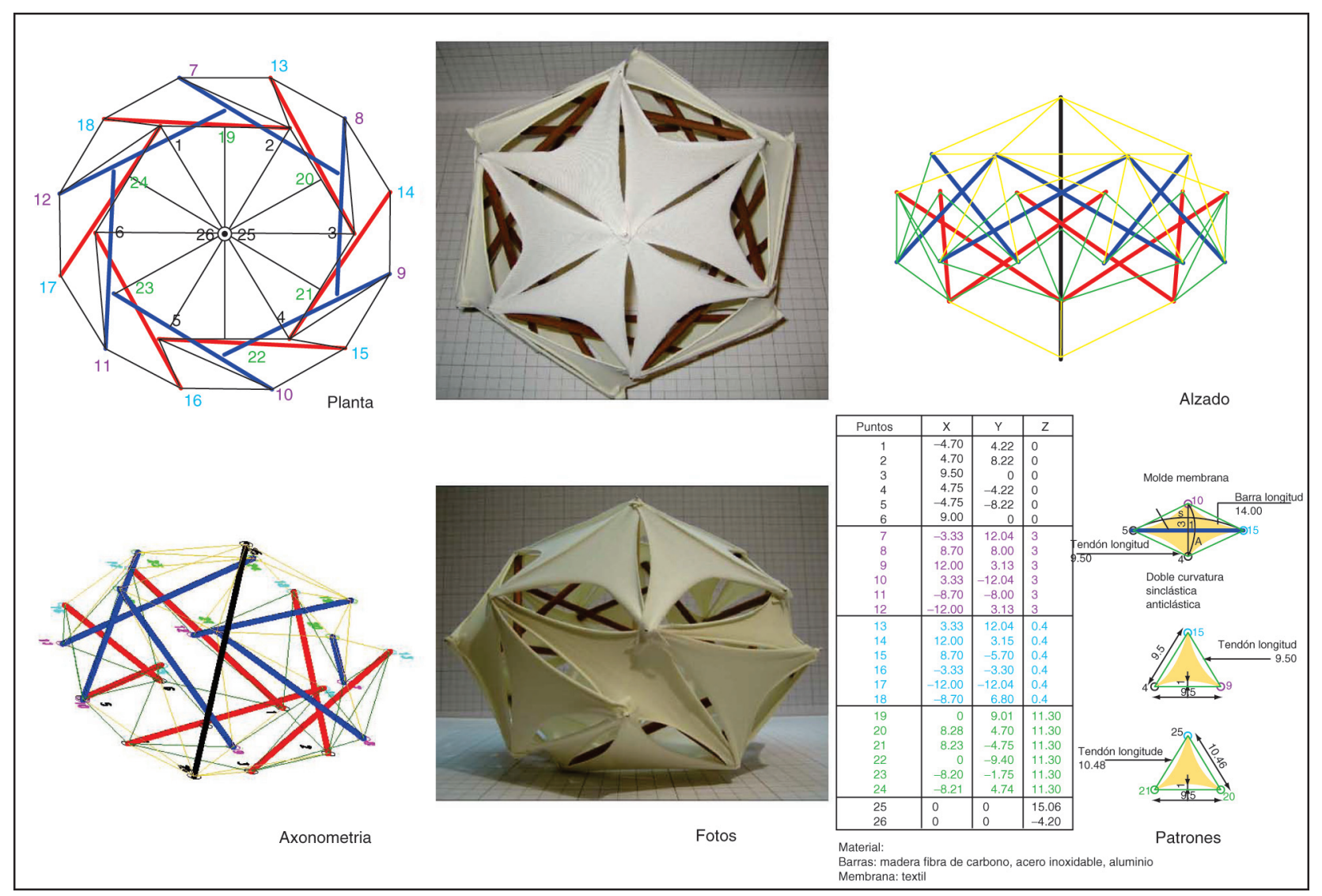

Figure 7. Tensegrity dome with twelve bars in a single layer with central mast - Geometric description

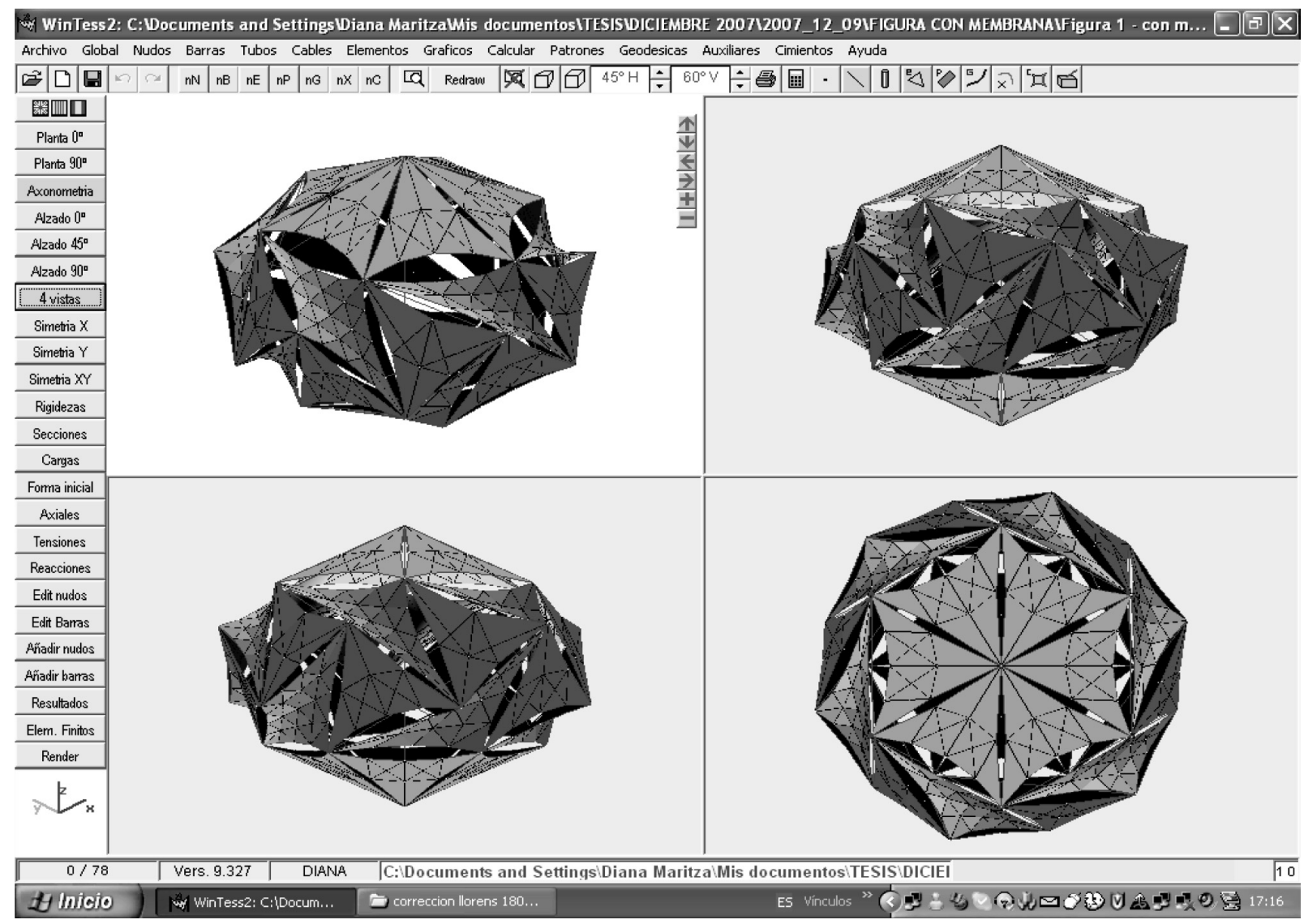

Figure 8. The structural analysis with WinTess considering self weight - The structure is in equilibrium 


\subsection{Classification}

Model Types - Membrane patterns (contribution of the author)

The process is generated by cutting textile membranes, rhombus or diamond shape patterns (rhombus $=$ major axis $17 \mathrm{~cm}$, minor axis $12 \mathrm{~cm}$ ), for the basic anti-prism unit of four bars $(\mathrm{L}=22 \mathrm{~cm})$, which are arranged in an oblique direction or diagonal position. The bars are joined to the end points of the membrane as shown in Fig 9. The bars are tied to the adjacent pattern on one of its vertexes, and so on. The tied up units can be closed by joining the first bar and the last membrane

(a) Diamond membrane pattern and struts in a single layer
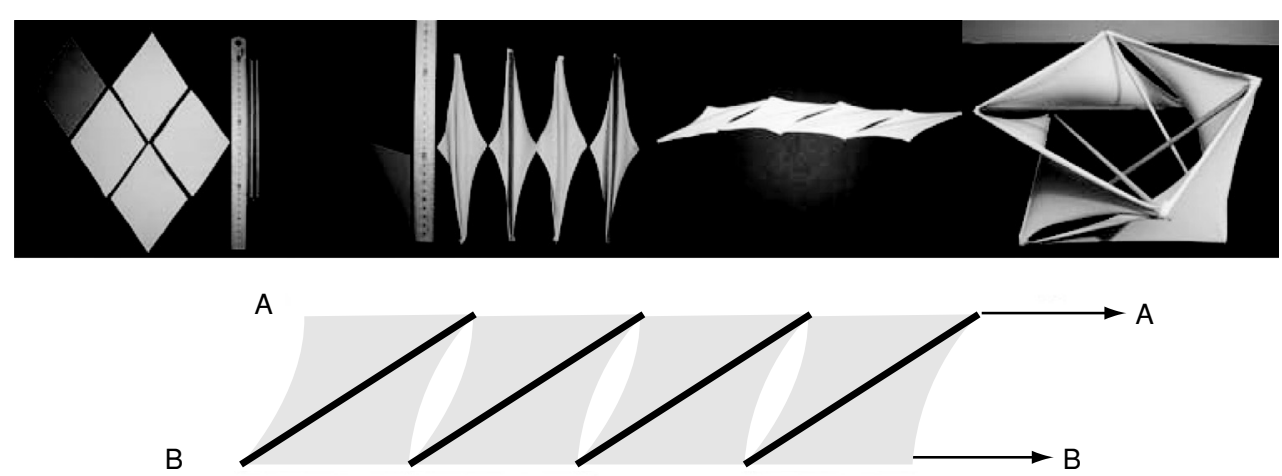

Figure 9. A tensegrity unit in a diamond pattern (an anti-prism of 4 struts)

pattern. The final anti-prism form has four paraboloids surfaces constructed from a flat rhombus. The initial position of the bars in this case is a single layer.

One can depart from the previously described process, and use a continuous rectangular membrane pattern $(15 \mathrm{~cm} \times 3.75 \mathrm{~cm})$ to find the form. The bars $(\mathrm{L}$ $=10 \mathrm{~cm}$ ) arranged in a single layer and joined to the end points of the membrane as shown in Fig 10. Finally the system is closed by joining the first bar and the last corner of the membrane. The initial location of the bars was determined by an orthogonal single mesh $(3.5 \mathrm{~cm} \times 3.5 \mathrm{~cm})$.
The equilibrium of this unit tensegrity anti-prism with four bars and continuous membrane pattern is achieved through the tension of the membrane. The final form is a continuum of four paraboloids.

In this tensegrity ring, formfinding is generated by means of a continuous membrane pattern $(7.00 \mathrm{~cm} \times$ $36.75 \mathrm{~cm}$ ), which has an initial rectangular form. For this model of twenty bars $(\mathrm{L}=10 \mathrm{~cm})$ in a double layer, the bars are arranged in an oblique direction or diagonal position, in alternate form and are joined to the end points of the membrane like shown in Fig 11, and resemble the veins of a leaf. Finally the system is

(b) Continuous membrane pattern and struts in a single layer
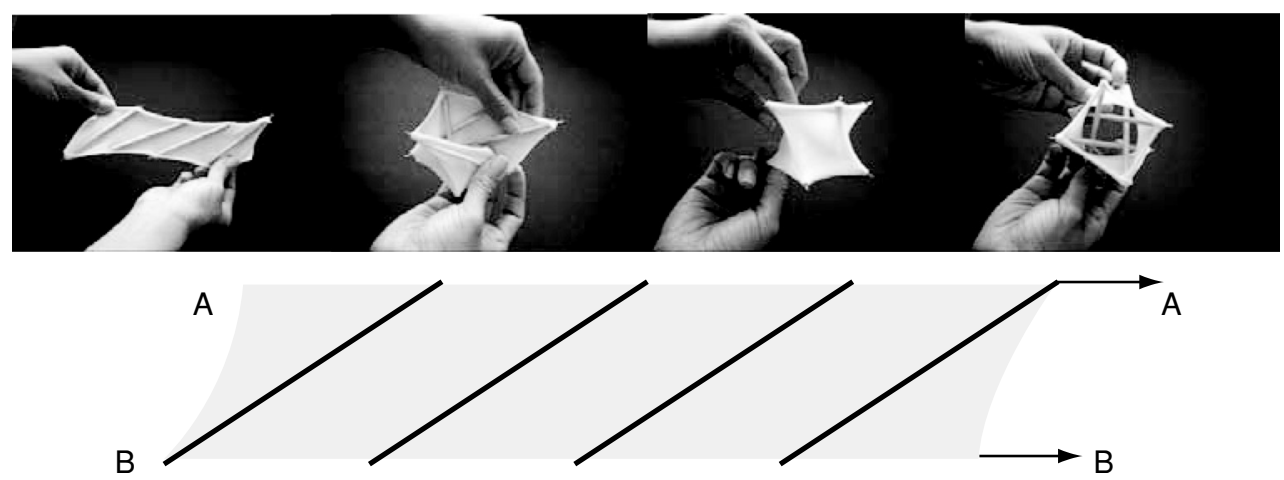

Figure 10. A tensegrity unit formed by continuous membrane pattern (an anti-prism of 4 struts) 
(c) Continuous membrane pattern with twenty struts in a double layer
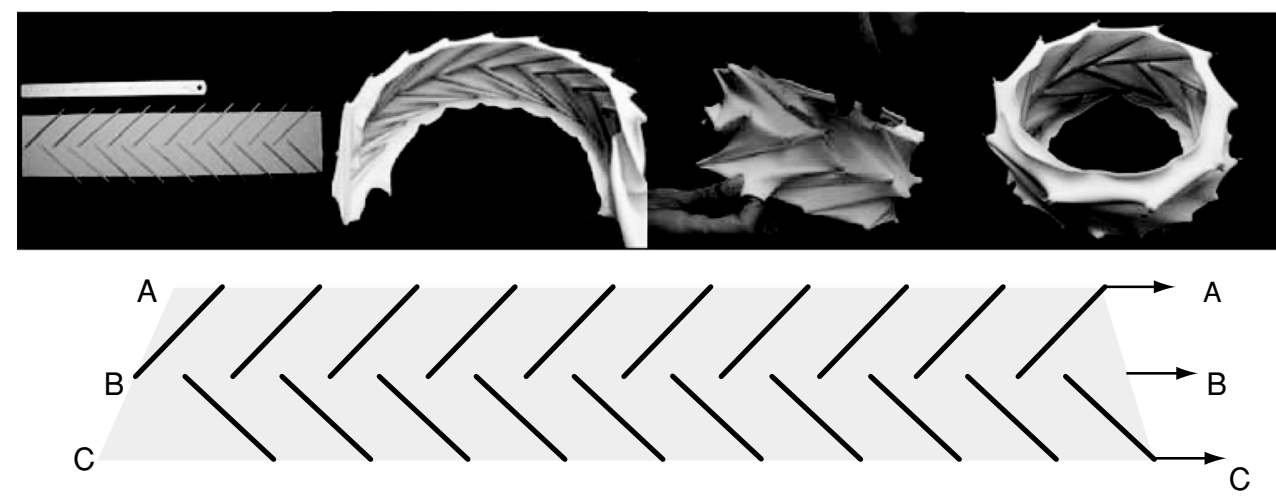

Figure 11. A tensegrity ring with continuous membrane pattern and 20 struts

closed by joining the first bars and the last corners of the membrane. The initial location of the bars was determined by an orthogonal double mesh $(3.5 \mathrm{~cm} \times$ $3.5 \mathrm{~cm}$ ), whose distance was defined by the elasticity of the membrane regarding the length of the diagonal bar. The final form is a continuum of ten paraboloids above and ten paraboloids below.

Formfinding is generated by means of a diamond membrane pattern (rhombus $=$ major axis $11.5 \mathrm{~cm}$, minor axis $4 \mathrm{~cm}$ ). This model is formed by two layers of twenty bars $(\mathrm{L}=20 \mathrm{~cm})$, which are arranged in an oblique direction or diagonal position. The bars are tied to the end points of the membrane as shown in Fig 12. Then the bars are joined to the adjacent pattern at one of the remaining free end points. The procedure is repeated with the adjacent pieces, which include the alternate ones of the lower level that are joined to the top bars at the adequate place of the pattern continuum. The last two bars close the system.

The final ring form is a continuum of ten paraboloids (on the upper level) and ten paraboloids (on the lower level). To cover the upper ring a supported central dome is proposed that creates an internal free space. The central dome is formed by a central mast $(\mathrm{L}=9 \mathrm{~cm})$ and several minor masts $(\mathrm{L}=6.5 \mathrm{~cm})$ placed in a circular form, which are held by the tension of the membrane. At the same time, the membrane helps to balance the system and joins the top dome with the tensegrity ring.

(d) Diamond membrane pattern and mesh with twenty struts in a double layer
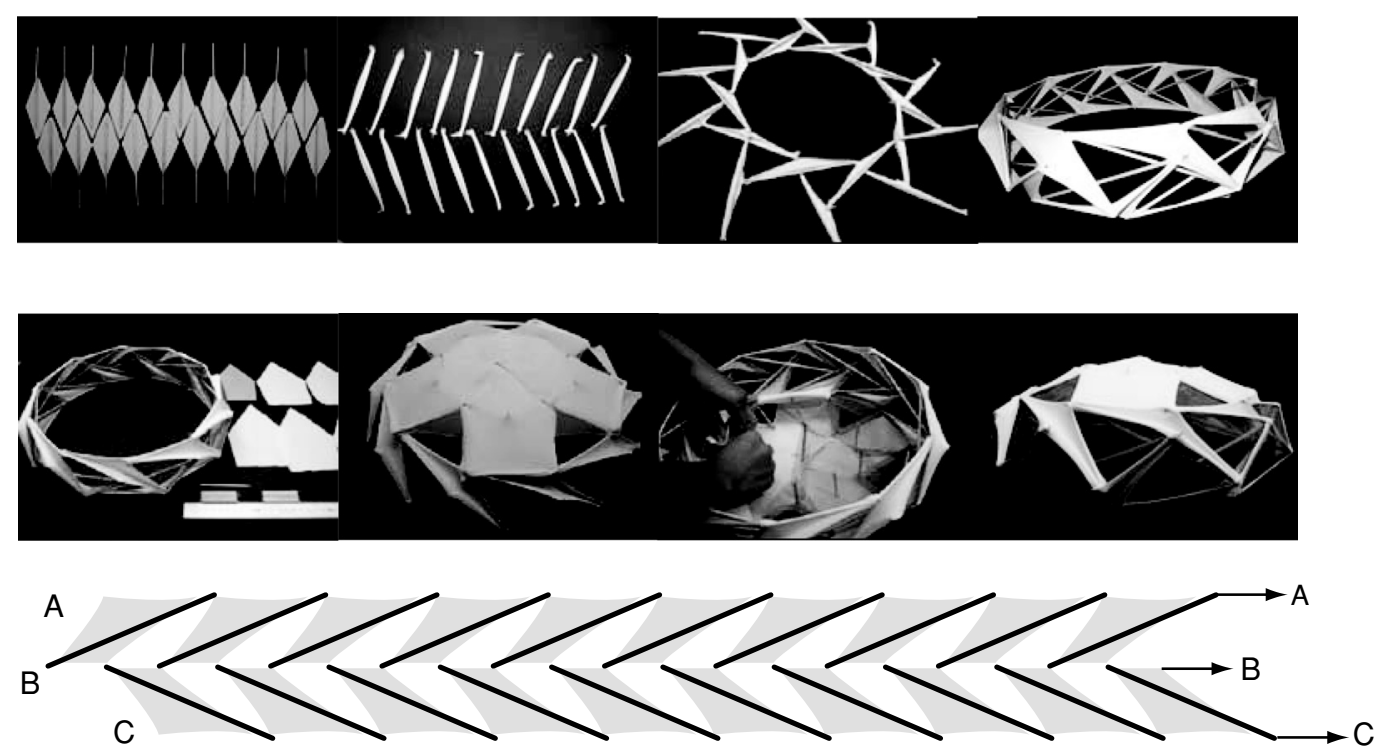

Figure 12. A tensegrity ring with a central dome and a diamond membrane pattern with 20 struts 
In this case, the top part of the model uses a textile membrane and the lower part uses a mesh with which it is possible to observe the location of the masts and the bars inside the structure.

Finally a $40 \mathrm{~cm}$ in diameter tensegrity structure has been completely constructed. To achieve a larger diameter, the number of bars would have to increase, but this must be proportional to the elasticity of the used membrane. Several models were constructed with major number of bars (24 - 30 struts). The material used (lycre) was not giving the sufficient stiffness when use more than 20 bars and for this reason there was chosen a scale model of 20 bars. If we increase the measure of the bars it is possible increase the diameter of the ring. (This is in progress to build a major scale prototype. Example: with 20 struts in a double layer $\mathrm{L}=50 \mathrm{~cm}$, then we obtain a tensegrity ring with $100 \mathrm{~cm}$ of diameter. The proportion length of bar to diameter is $1: 2$ )

If one compares the model in Fig 12 with the continuous membrane in Fig 11 it can be observed that though they have the same number of bars, the diameter of model in Fig 12 is larger, approximately double, and for this reason the diamond pattern model was selected to continue with the structural analysis by means of WinTess software.

\subsection{Formfinding by WinTess software}

Form finding is generated using WinTess software [6]. First, an orthogonal 40 point mesh was constructed where the coordinates $(\mathrm{x}, \mathrm{y}, \mathrm{z})$ came from the chosen model (Fig 12). After introducing the coordinates and defining the elements like: membranes, border cables, external cables, tubes, etc. with their respective structural characteristics and proper weight; a static equilibrium analysis of the prestressed membrane structure was performed. The balance is achieved because all the compression and tension forces are perfectly distributed, that is to say they work jointly, where the structural form is guaranteed, because finally the system is closed and auto-balanced.
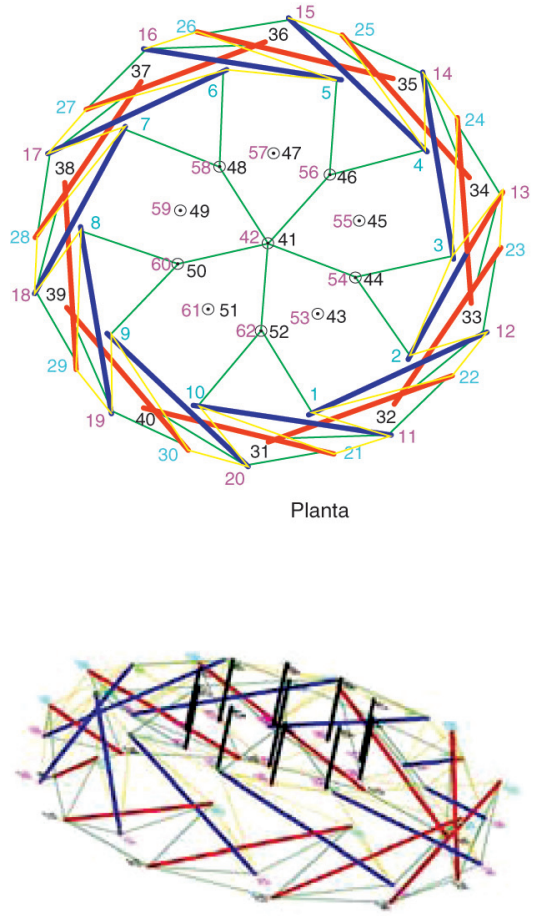

Axonometria
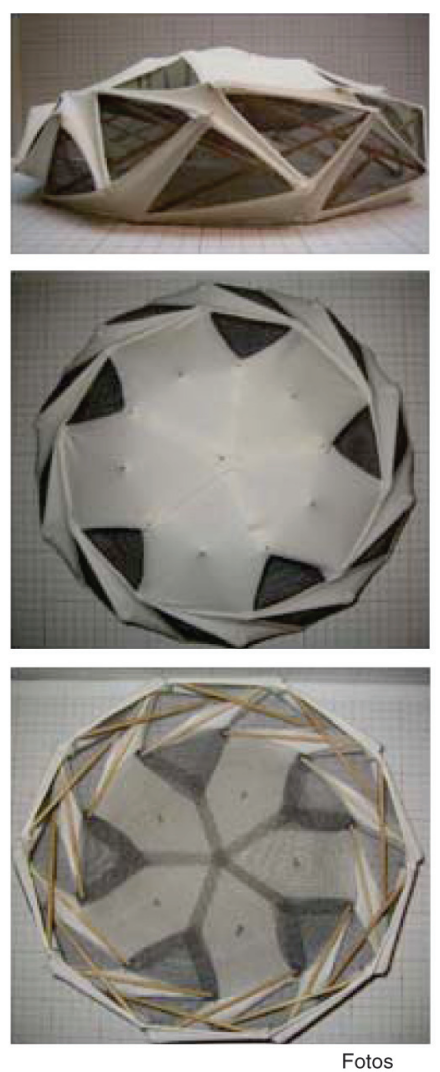

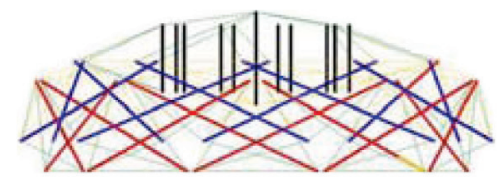

Alzado

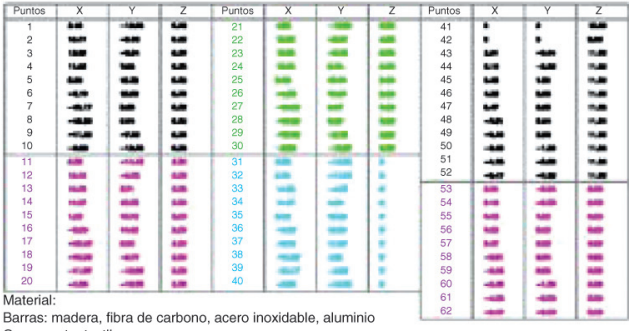

Barras: madera, fitac
Cerramento: texti
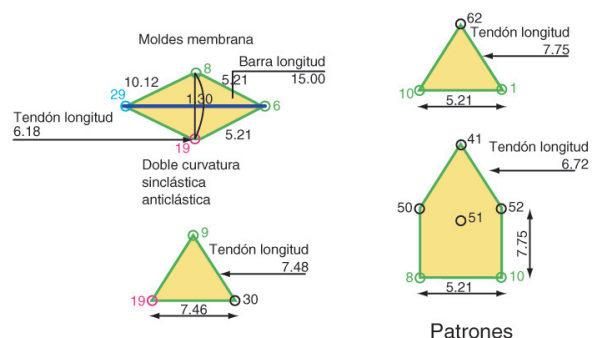

Figure 13. Stucture drawing with AutoCAD-Geometric description. The tensegrity ring and the central dome were represented with membrane and a net of cables 

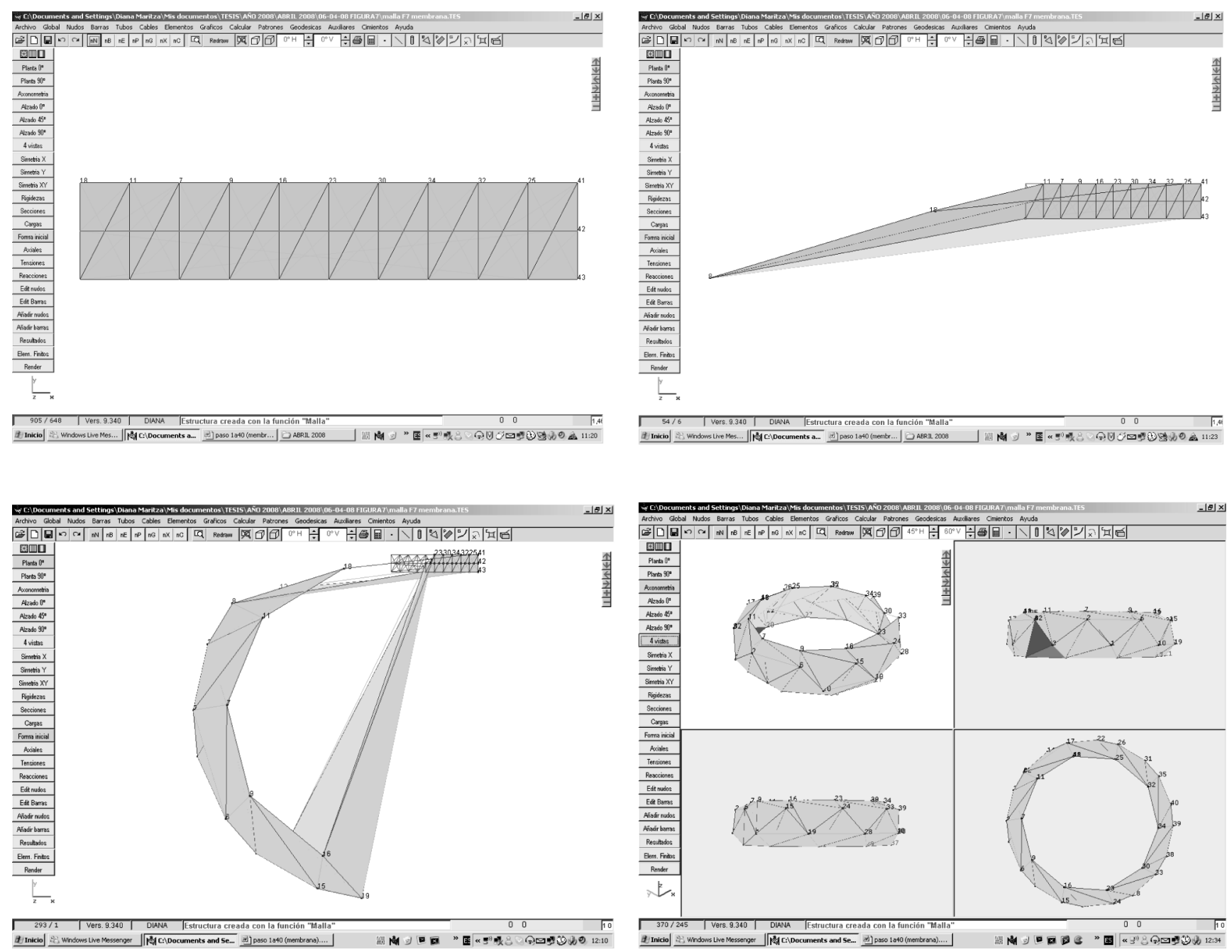

Figure 14. A tensegrity ring generated by WinTess. The tensegrity ring is represented with membrane and a net of cables to prevent the movements of the systems

\section{STRUCTURAL ANALYSIS}

Tensegrity structures are characterized because of their: [7]

- Discontinuous elements that work under compression,

- Prestressed structure,

- Auto-balanced structure.

In the following analysis the model is tested for external loads, first for wind at $170 \mathrm{~km} / \mathrm{h}$, and then for $50 \mathrm{~kg} / \mathrm{m}^{2}$ of snow. The tensegrity ring has sufficient stiffness to withstand the wind, however the major horizontal displacement is of $1143 \mathrm{~mm}$, therefore the central dome moves also, hence it is necessary to use external elements to prevent the displacement and probably the collapse of the structure.

Pressure changes, depending on the direction of the wind over the membrane, and deforms and creates points of suction (dynamic pressure for $150 \mathrm{~km} / \mathrm{h}$ wind over the membrane is $100 \mathrm{~kg} / \mathrm{m}^{2}$ approximately). In case of snow, the central dome has a vertical displacement of $800 \mathrm{~mm}$ at the membrane where the maximum stress is located.

Exterior cables and tubes are proposed to prevent these exceptional displacements. The exterior tubes are placed surrounding the ring so that they continue in the direction of the forces coming from the top 


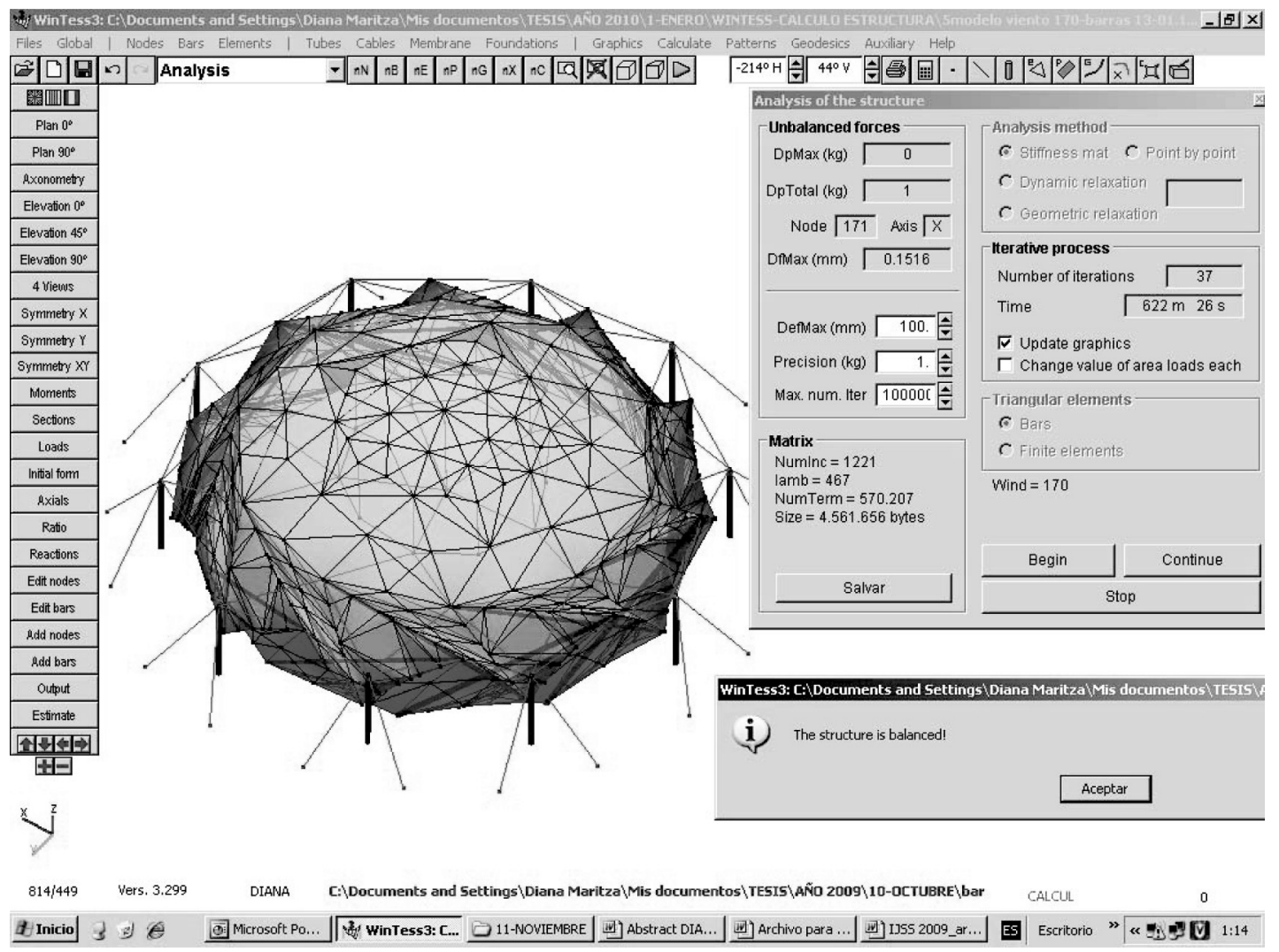

Figure 15. Structural analysis by WinTess-Wind $170 \mathrm{~km} / \mathrm{h}$ - Structure is represented with membrane and a net of cables to prevent the movements of the system

membrane dome. The pretension cables can then increase the stiffness of the structure, and contribute to support the balance of the system.

Structural characteristics of the model elements:

- Membrane: Ferrari Fluotop T2 1202 - Prestress 1. $\%=32.5 \mathrm{daN} / 5 \mathrm{~cm}=650 \mathrm{~kg} / \mathrm{m}$ Resistance $\mathrm{Rk}=560 / 560 \mathrm{daN} / 5 \mathrm{~cm}=11200,0 \mathrm{~kg} / \mathrm{m}$ - Safety factor (5) $=\mathrm{Rd}=\mathrm{Rk} / 5=112 \mathrm{daN} / 5 \mathrm{~cm}=2240 \mathrm{~kg} / \mathrm{m}$

- Border cables (Boltrope): $1 \times 91(36 \mathrm{~mm})$ Inox 36 - Section $753 \mathrm{~mm}^{2}$ - Elasticity modulus $1.380 \mathrm{t} / \mathrm{cm}^{2}=138 \mathrm{kN} / \mathrm{mm}^{2}-\mathbf{Q}=87,21 \mathrm{t}=872,1 \mathrm{kN}$
- External cables (Guyrope): WS-2 $(36 \mathrm{~mm}) \mathrm{Galv}$ 36 - Section $855 \mathrm{~mm}^{2}$ - Elasticity modulus 1.635 $\mathrm{t} / \mathrm{cm}^{2}=163,5 \mathrm{kN} / \mathrm{mm}^{2}-\mathbf{Q}=125,46 \mathrm{t}=1.254,6$ $k N$

- Tubes of the ring: $L=20 m-400-10 \_S 235$ Section $122,522 \mathrm{~cm}^{2}$ - Elasticity modulus $2.100 \mathrm{t} / \mathrm{cm}^{2}=210 \mathrm{kN} / \mathrm{mm}^{2}$ - Density $7,85 \mathrm{t} / \mathrm{m}^{3}=$ $78,5 \mathrm{kN} / \mathrm{m}^{3}$

- Central mast of the dome: $L=9 m-110-5 \_S 235$ Section $16,493 \mathrm{~cm}^{2}$ - Elasticity modulus $2.100 \mathrm{t} / \mathrm{cm}^{2}$ $=210 \mathrm{kN} / \mathrm{mm}^{2}$ - Density 7,85 $\mathrm{t} / \mathrm{m}^{3}=78,5 \mathrm{kN} / \mathrm{m}^{3}$
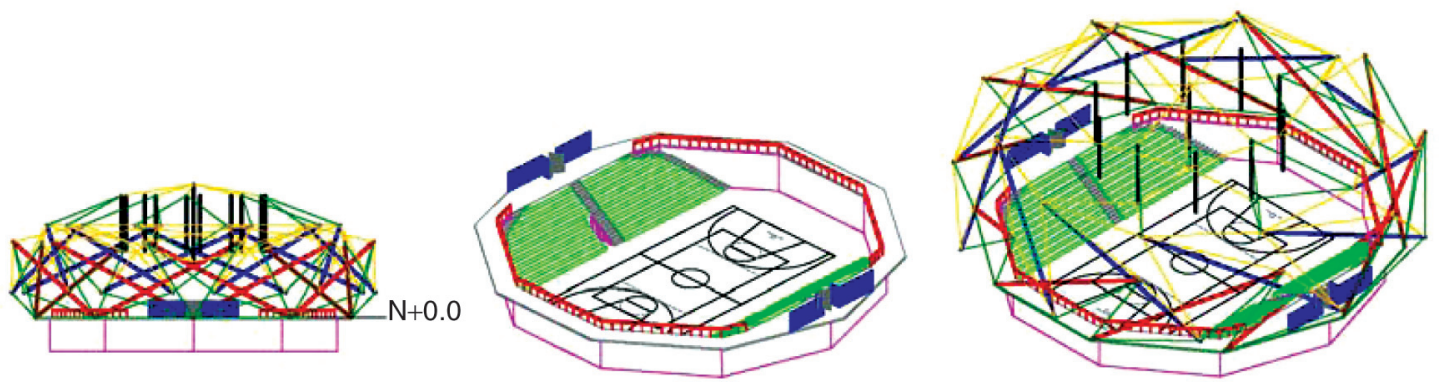

Figure 16. Application of the tensegrity ring to cover a sports arena 
- Minor masts of the dome: $L=6,5 m-90$ 4_S235 - Section $10,807 \mathrm{~cm}^{2}$ - Elasticity modulus $2.100 \mathrm{t} / \mathrm{cm}^{2}=210 \mathrm{kN} / \mathrm{mm}^{2}$ - Density $7,85 \mathrm{t} / \mathrm{m}^{3}=$ $78,5 \mathrm{kN} / \mathrm{m}^{3}$

- $\quad$ External tubes: L $=8 m-250-8 \_S 235$ - Section $60,821 \mathrm{~cm}^{2}$ - Elasticity modulus $2.100 \mathrm{t} / \mathrm{cm}^{2}=$ $210 \mathrm{kN} / \mathrm{mm}^{2}$ - Density $7,85 \mathrm{t} / \mathrm{m}^{3}=78,5 \mathrm{kN} / \mathrm{m}^{3}$

Table 1. General data

\begin{tabular}{lr}
\hline \multicolumn{2}{c}{ Structure general data } \\
\hline Number of nods & 447 \\
Number of bars & 1296 \\
Number of tubs & 41 \\
Number of elements & 709 \\
Number of cables & 305 \\
Covered surface & $1.177,08 \mathrm{~m}^{2}$ \\
Volume (between membrane & \\
$\quad$ and plane Z = 0) & $15.818 \mathrm{~m}^{3}$ \\
Membrane surface & $2.959,96 \mathrm{~m}^{2}$ \\
Weight of the bars & $53.807,38 \mathrm{~kg}$ \\
Weight of the membrane & $3.847,94 \mathrm{~kg}$ \\
Membrane elongation modulus & $65 \mathrm{~T} / \mathrm{m}$ \\
\hline
\end{tabular}

\section{APPLICATION}

There exists a need for roof structures that can cover big surfaces and spaces, but free of any interior supports. After doing the pertinent calculations, a tensegrity ring is proposed with a central dome, using diamond membrane patterns with twenty struts in a double layer, to cover a $40 \mathrm{~m}$ diameter sports arena, which has a surface of $1.200 \mathrm{~m}^{2}$ and may be occupied by 626 persons, approximately.

\section{CONCLUSIONS}

This methodology allows these conclusions:

- Tensegrity is not a conventional structure.

- The balance is solved by formfinding, constructive methods and pretension possibilities, where models of continuous membranes and diamond patterns, with bars in a single layer or double layer are proposed.

- It is essential to know the initial state system (pretension and stiffness of the elements that compose it) and its behaviour when it is subjected to external actions.

- Tensegrity structures are kinematically weak and need geometrical stiffening elements, such as tension elements. [8]
- The analysis of the forces in the components is important, considering endogenous factors, like the internal prestress of the structure and exogenous factors, such as external loads, points of support, anchorages, etc.

- The major stress distribution given by the WinTess software shows the importance of property selection in the elements (to define dimensions). In addition it is observed that a safety coefficient is important to take account for the calculation.

- The difficulty of these systems lies in the fact that though they are auto-balanced, with external loads such as wind and snow, it is necessary to increase the stiffness of the elements and moreover they should be reinforced by external tubes, which help to prevent a collapse of the system in particular conditions.

- The system stiffness is achieved through the membrane prestress and auxiliary external elements such as tubes and cables.

- These systems are flexible in the $\mathrm{Z}$ axis, which makes them useful as elements or folding and unfolding systems. [9]

- To verify the hypotheses that are propose here, a major scale prototype will be constructed and a wind tunnel test will be performed also.

\section{REFERENCES}

[1] Fuller, R. B., Synergetics, MacMillan, New York, 1975.

[2] Snelson, K., Continuous tension, discontinuous compression structures, US. Patent No.3,169,611 Febrero 16, 1965.

[3] Pugh, A., An Introduction to Tensegrity, University of California Press, Berkeley, 1976.

[4] Jáuregui, V., Tensegrity Structures and their Application to Architecture, Master Thesis in Architecture, Queen's University Belfast -UK., 2004.

[5] Pérez, N., Folding Closed Tensegrity, Thesis in Architecture, University National of Colombia, Bogotá, 2003.

[6] Sastre, R., Disseny i Càlcul d'Estructures de Barres Totalment Articulades amb Grans Deformacions, Ph.D. Thesis, Department of Architectural Technology I - UPC, Barcelona, 1981.

[7] Llorens, J., García Ch. y Pöppinghaus H., Tensegrity Structures for Textile Roofs, Textile Composites and Inflatable structures, E. Oñate and B. Kröplin (Eds.), Cimne, Barcelona, 2003.

[8] Wagner, R., Tensegrity and Cable Domes, The Seventh International Workshop on the Design and Practical Realisation of Architectural Membranes, Berlin, 2002.

[9] Motro, R., and Smaili, A., Foldable/Unfoldable Curved Tensegrity Systems by Finite Mechanism Activation, Journal of The International Association For Shell and Spatial of Structures, Vol. 48, No. 3, Dec n.155, 2007. 
